\title{
Beta radiation from snow
}

SIR-We have detected radioactive snow in a 6-metre-deep snowpit at a site 38 kilometres northeast of the South Pole. We would like to report here our ideas about the cause and significance of this beta-radiation.

We have examined the depth profile of samples collected at $5-\mathrm{cm}$ intervals from the pit, and we find an annual signal in the beta-radioactivity profile during 1955 to 1974 , presumably resulting from the intrusion of stratospheric air into the troposphere each summer. But we found an unexpected peak in beta-radioactivity in samples at $10-20-\mathrm{cm}$ depth (see figure).

Examination of the profiles of $\mathrm{Na}^{+}, \mathrm{Cl}^{-}, \mathrm{Cl}^{-}$ $\mathrm{Na}^{+}$and of $\mathrm{H}_{2} \mathrm{O}_{2}$ indicate that the depth interval 10-20-cm represents snow deposited in the summer of 1987-88. Gamma - spectrometric analysis shows that ${ }^{137} \mathrm{Cs}$, at levels of $0.23 \pm 0.20$ and $1.25 \pm 0.11 \mathrm{pCi} \mathrm{kg}^{-1}$ (in the 10-15 and 15-20 cm samples, respective-

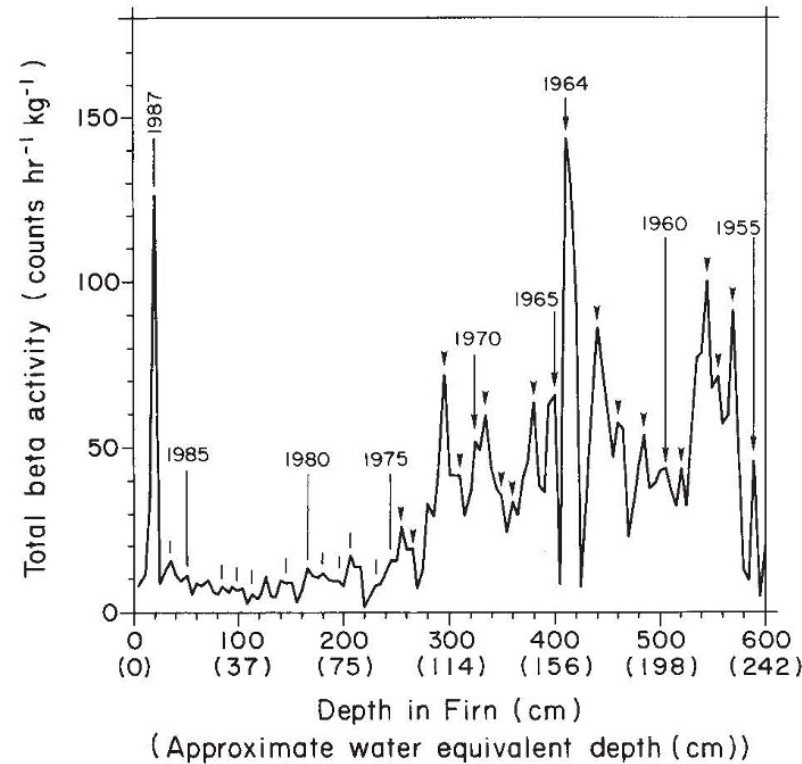

subsidence of stratospheric air within the vortex of the Antarctic ozone hole, although it is not clear that this air descends to the surface.

The concentration of the cosmogenic radionuclide ${ }^{7} \mathrm{Be}$ in Antarctic aerosol has been shown be a tracer of stratospheric air reaching the surface. Although the

Depth profile of total beta-radioactivity in the snowpit, sampled in December 1988. The unexpected peak in beta-radioactivity at $10-20-\mathrm{cm}$ depth results from the presence of ${ }^{137} \mathrm{Cs}$. ly), is responsible for the elevated betaradioactivity.

The source of the ${ }^{137} \mathrm{Cs}$ is problematic. The Chernobyl reactor accident in 1986 could be one explanation; deposition of debris 20 months after the accident is in good agreement with the lag in bomb fallout from Northern Hemisphere atmospheric tests. But there is no ${ }^{134} \mathrm{Cs}$, the characteristic fallout isotope from Chernobyl, in the labelled layer. The relatively small samples from the top of the snowpit make detection and quantification of radioactivity at these levels difficult, so an explanation involving Chernobyl cannot be excluded.

If Chernobyl debris was deposited at the South Pole, it must have been transported in the stratosphere. Although most of the radioactive material from Chernobyl remained in the troposphere, some of the debris did penetrate the tropopause. If there was Chernobyl debris in the stratosphere, why was no fallout reported in the Southern Hemisphere?

The apparent restriction of recent radioactive fallout in Antarctica (and perhaps the entire Southern Hemisphere) to the region near South Pole suggests that the polar vortex may have focused stratospheric fallout onto the central Antarctic plateau. There is pronounced relationship between aerosol and snow concentrations of ${ }^{7} \mathrm{Be}$ have not been firmly established, a limited data set of ${ }^{3} \mathrm{Be}$ concentrations in Antarctic snow indicates much greater stratospheric influence in the centre of the Antarctic polar vortex.

The presence of Chernobyl debris in the snow near the South Pole would have important implications about atmospheric transport to the Antarctic Plateau, and could provide a valuable new reference horizon for researchers working in this region. But our results, from a single snowpit, are far from conclusive. The preservation of Chernobyl debris on the Greenland ice sheet is very uneven, and the ${ }^{137} \mathrm{Cs}$ snow near the South Pole is probably at least as patchily distributed, suggesting that very careful sampling of a number of pits is needed to quantify the amount of ${ }^{137} \mathrm{Cs}$ that has recently been delivered to this remote area.

JACKE. DIBB

PAULA. MAYEWSKI CHRISTOPHER S. BUCK SCOTT M. DRUMMEY

Glacier Research Group,

Institute for the Study of Earth,

Oceans and Space,

University of New Hampshire,

Durham,

New hampshire 03824-3525, USA

\section{Magnetic isotope effect}

SIR-The magnetic isotope effect - the dependence of the rate of chemical interactions between radicals on the spins and magnetic moments of their nuclei - is a remarkable phenomenon ${ }^{1}$. It results in the selection and redistribution of magnetic and non-magnetic isotopes among the different products of radical reactions. The effect is known for ${ }^{13} \mathrm{C}$ (refs 2,3 ), ${ }^{17} \mathrm{O}$ (ref. 4) and ${ }^{29} \mathrm{Si}$ (ref. 5). Most recently ${ }^{5}$, it has been claimed for ${ }^{235} \mathrm{U}$. We have now measured the effect for ${ }^{33} \mathrm{~S}$.

The photolysis of phenyl-acyl-phenylsulphone $\left(\mathrm{PhCOCH}_{2} \mathrm{SO}_{2} \mathrm{Ph}\right.$, or I) in SDS micelles is accompanied by the separation of sulphur isotopes: the starting ketone $\mathbf{I}$ is enriched in the heavy isotopes ${ }^{33} \mathrm{~S}(2.4 \%)$ and ${ }^{34} \mathrm{~S}(0.6 \%)$ with respect to the light non-magnetic isotope ${ }^{32} \mathrm{~S}$ and about $80 \%$ conversion of $\mathbf{I}$. The enrichment of non-magnetic ${ }^{34} \mathrm{~S}$ nuclei is probably due to the classical massdependent isotope effect, however, the measured enrichment of the magnetic isotope ${ }^{33} \mathrm{~S}$ is four times that of ${ }^{34} \mathrm{~S} .{ }^{33} \mathrm{~S}$ enrichment would be expected to be less than that of ${ }^{34} \mathrm{~S}$ if the mass-dependent effect were the sole cause.

We suggest that this discrepancy is explained by the magnetic properties of ${ }^{33} \mathrm{~S}$, whose nuclei have spin $3 / 2$ and a magnetic moment of 0.643 . The immediate product of photolysis of I will be the radical pair $\mathrm{PhCOCH}_{2}$ and $\mathrm{SO}_{2} \mathrm{Ph}$ in the triplet electronspin state. Triplet-singlet intersystem crossing governed by electron-nuclear hyperfine interaction will induce recombination of the ketone I, but the hyperfine interaction of the magnetic ${ }^{33} \mathrm{~S}$ nuclei will accelerate triplet singlet conversion of radical pairs in which it is contained, increasing its abundance in the regenerated ketone. On the other hand, triplet-singlet conversion of radical pairs containing the non-magnetic sulphur nuclei ${ }^{34} \mathrm{~S}$ and ${ }^{32} \mathrm{~S}$ will be less rapid, with the result that radical pairs containing these nuclei will more often be transformed into products other than $\mathbf{I}$.

EUGENII N. STEP

VALERII F. TARASOV ANATOLII L. BUCHACHENKO

N. N. Semenov Institute of

Chemical Physics,

USSR Academy of Sciences,

Ulitsa Kosygina 4,

117334 Moscow, USSR

1. Buchachenko, A. L. in Prog. React. Kinet. 13, 164-220 (1984).

2. Buchachenko, A. L. etal. Doki. Acad. Nauk SSSR 228, 379 (1976).

3. Sagdeev, R. Z. et al. Chem. Phys. Lett. 48, 89 (1977).

4. Buchachenko, A. L. \& Yasina, L. L. Dokl. Acad. Nauk SSSR 260, 431 (1980).

5. Step, E.N., Tarasov, V. F. \& Buchachenko, A. L. Izv. Acad. Nauk SSSR 1, 212 (1988). 